\title{
Total Synthesis of Celogentin $\mathbf{C}^{* *}$
}

\author{
Bing Ma, Dmitry N. Litvinov, Dr. Liwen He, Dr. Biplab Banerjee, and Prof. Steven L. Castle*
} Department of Chemistry and Biochemistry Brigham Young University, Provo, UT 84602 (USA)

\section{Keywords}

natural products; oxidative coupling; peptides; radical reactions; total synthesis

The bicyclic octapeptide celogentin C (1, Figure 1) was isolated by Kobayashi and coworkers from the seeds of Celosia argentea. ${ }^{[1]}$ Other structurally similar natural products include the bicyclic peptides moroidin, ${ }^{[2]}$ celogentins $\mathrm{A}-\mathrm{H},{ }^{[3]}$ and celogentin $\mathrm{J},{ }^{[3]}$ as well as the monocyclic peptides celogentin $\mathrm{K}^{[4]}$ and stephanotic acid. ${ }^{[5]}$ Some of these compounds inhibit tubulin polymerization, ${ }^{[6]}$ with 1 ranking as the most potent antimitotic agent of this natural product family. The unusual structure of 1 is derived from two cross-links between amino acid side chains. A bond between the leucine $\beta$-carbon atom and the indole $\mathrm{C} 6$ of tryptophan forms the left-hand ring of 1 , whereas the right-hand macrocycle contains a $\mathrm{C}-\mathrm{N}$ linkage between the indole $\mathrm{C} 2$ and the imidazole N1. The resultant heterobiaryl axis introduces the potential of atropisomer stereochemistry. The combination of useful biological activity and intriguing architecture has prompted numerous synthetic efforts targeting 1 and related compounds. ${ }^{[7-10]}$ However, a total synthesis of one of the bicyclic members of the celogentin family has not yet been reported. ${ }^{[11]}$ Herein, we describe our efforts which have culminated in the synthesis of celogentin C.

Our synthetic plan is outlined in Figure 1. We previously constructed the right-hand ring of 1 by using an intermolecular indole-imidazole oxidative coupling and subsequent macrolactamization at the Pro-Arg site. ${ }^{[7 a]}$ We envisioned utilizing our radical conjugate addition methodology $[12,13]$ to prepare the $\beta$-substituted $\alpha$-amino acid moiety resulting from union of the Leu and Trp side chains. The radical acceptor would be fashioned by means of a Knoevenagel condensation. After the radical conjugate addition, formation of the left-hand ring of 1 was to be accomplished by macrolactamization at the Val-Trp site. The approach was designed to be flexible in terms of the order of ring closures; however, attempts to append the left-hand ring onto the right-hand ring were unsuccessful. ${ }^{[14]}$ Consequently, we embarked upon a left-to-right-sequence.

The first key reaction encountered in this route was the Knoevenagel condensation. The preparation of the condensation partners is detailed in Scheme 1. Tryptophan 2, possessing a

\footnotetext{
** We thank Brigham Young University and the National Institutes of Health (GM70483) for support of this work. We also thank Prof. Hiroshi Morita of Hoshi University for providing an analytical sample of celogentin C and Joshua W. Robinson for assistance in preparing compound 2.

FFax: (+ 1)801-422-0153 scastle@ chem.byu.edu Homepage: http://people.chem.byu.edu/scastle.

Supporting information for this article is available on the WWW under http://dx.doi.org/10.1002/anie.200902425.
} 
silyloxymethyl group at C6 of the indole, was constructed previously by using a combination of phase-transfer-catalyzed asymmetric alkylation and $\mathrm{Pd}$-catalyzed heteroannulation. ${ }^{[7 \mathrm{c}]}$ Silyl ether cleavage and oxidation of the resulting benzylic alcohol with DDQ afforded aldehyde 3 in good yield. The nitroacetamide coupling partner of 3 was fashioned from the dipeptide Leu-Val-OBn (4) ${ }^{[15]}$ by means of Rajappa's methodology. [16] Thus, condensation of 4 with commercially available dithioketene acetal 5 in the presence of catalytic TsOH provided vinyl sulfide 6 as a single alkene isomer of undetermined configuration. The nitroacetamide moiety of 7 was then revealed by exposure of 6 to $\mathrm{HgCl}_{2}$ in aqueous $\mathrm{MeCN}$.

The condensation of $\mathbf{3}$ and $\mathbf{7}$ occurred in the presence of $\mathrm{TiCl}_{4}$ and $\mathrm{NMM},{ }^{[17]}$ affording a, $\beta$ unsaturated a-nitro amide $\mathbf{8}$ as a single alkene isomer (Scheme 2). ${ }^{[18]}$ Optimal yields in this reaction were obtained with a 2:1 mixture of THF and $\mathrm{Et}_{2} \mathrm{O}$ as solvent. Based on previous studies with model substrates, we were hopeful that Mg-DBFOX (DBFOX = 4,6dibenzofurandiyl-2,2'-bisoxazoline) chiral Lewis acids would promote a stereoselective radical conjugate addition to $\mathbf{8}$, but neither $\mathrm{DBFOX} / \mathrm{Ph}^{[12 \mathrm{~b}]}$ nor our second-generation DBFOX catalysts ${ }^{[12 \mathrm{a}]}$ afforded the adducts with any degree of selectivity. In fact, the best diastereomeric ratio, albeit low (1.0:2.9:2.0:1.2), was acquired by employing substrate stereocontrol in conjunction with the achiral Lewis acid $\mathrm{Zn}(\mathrm{OTf})_{2}$. Although the stereoselectivity of the radical conjugate addition was modest, the yield was excellent, as a mixture of amines 9 a-d was obtained in $90 \%$ yield after nitro group reduction by $\mathrm{SmI}_{2}$. The two minor isomers $9 a$ and $9 d$ could be removed at this stage, leaving a 1.5:1 mixture of $9 \mathbf{b}$ and 9c. Since the yield of $\mathbf{9 b}$ was a reasonable $36 \%$ over these two steps, we felt that this protocol would enable us to synthesize $\mathbf{1}$ provided the configuration of $\mathbf{9 b}$ at the two newly formed stereocenters matched the natural product. Accordingly, we resolved to convert $\mathbf{9 b}$ into a species that could be compared spectroscopically to a known compound.

Coupling of the mixture of amines $9 \mathbf{b}$ and $9 \mathbf{c}$ to pyroglutamic acid provided peptides $\mathbf{1 0 b}$ and 10c in $96 \%$ yield, but separation was not possible at this stage. Fortunately, cleavage of the $\mathrm{Cbz}$ and benzyl ester moieties under transfer hydrogenolysis conditions afforded a separable mixture of unprotected peptides 11b and 11c. Despite the low diastereoselectivity of the radical conjugate addition, diastereomerically pure $\mathbf{1 1 b}$ was obtained in $31 \%$ yield from Knoevenagel adduct $\mathbf{8}$ due to the excellent yields of the four intervening steps.

In light of the considerable epimerization encountered by Moody and co-workers in a related macrolactamization, ${ }^{[11]}$ we were relieved to find that HOBt/HBTU-mediated cyclization of $\mathbf{1 1 b}$ delivered $\mathbf{1 2 b}$ as a single detectable diastereomer in $91 \%$ yield. We attribute this difference to the fact that Moody and co-workers formed their macrocycle at a site corresponding to the Leu-Val peptide bond in $\mathbf{1 2 b}$, whereas our cyclization occurs at the Val-Trp peptide bond. Then, simultaneous removal of the tert-butyl ester and triethylsilyl groups was accomplished by the action of $B$-bromocatecholborane, ${ }^{[19]}$ and subsequent methyl esterification provided $\mathbf{1 4 b}$. This compound is closely related to stephanotic acid methyl ester, a natural product derivative previously synthesized by the Moody group ${ }^{[11]}$ with identical configuration to the left-hand ring of $\mathbf{1}$. By comparison of ${ }^{1} \mathrm{H}$ NMR data, particularly for hydrogen atoms directly attached to the macrocycle, we tried to determine whether or not $\mathbf{1 4 b}$ possessed the requisite configuration for conversion into $\mathbf{1}$. We 
discovered that the ${ }^{1} \mathrm{H}$ NMR data of $\mathbf{1 4 b}$ and stephanotic acid methyl ester matched extremely well, ${ }^{[20]}$ thereby giving us confidence that the major isomer obtained from the radical conjugate addition was of identical configuration to $\mathbf{1}$.

The stereochemical assignment of $\mathbf{1 4 b}$ was confirmed by conversion of acid $13 \mathrm{~b}$ into celogentin $\mathrm{C}$ as illustrated in Scheme 3. Thus, coupling of $\mathbf{1 3 b}$ with Pro-OBn afforded hexapeptide 15, the substrate for the crucial oxidative coupling reaction. ${ }^{[21]}$ In contrast to previous results with simpler substrates, ${ }^{[7 \mathrm{a}]}$ the oxidative coupling of $\mathbf{1 5}$ and Arg- His dipeptide $16^{[7 \mathrm{a}]}$ lead to formation of a byproduct, and the desired product was not detected. Mass spectrometry data indicated the presence of an additional chlorine atom in the undesired compound, and ${ }^{1} \mathrm{H}$ NMR spectra of crude reaction mixtures showed significant changes in the chemical shifts of the proline hydrogen atoms. This suggested that the unwanted chlorination was taking place on the proline residue. Fortunately, a serendipitous discovery demonstrated the effectiveness of the oxidative coupling when Pro-OBn was present in the reaction mixture. Optimized conditions enlisted 2 equiv of Pro-OBn in conjunction with 3 equiv of NCS, and an excess of $\mathbf{1 6}$ (5 equiv) was required to ensure a satisfactory reaction rate. Separation of the oxidative coupling product from unreacted $\mathbf{1 6}$ was most easily accomplished after $\mathrm{Cbz}$ and $\mathrm{OBn}$ deprotection. In this way, octapeptide $\mathbf{1 7}$ could be formed in $64 \%$ yield over two steps from 15.

One possible explanation for the role of Pro-OBn in the oxidative coupling reaction is provided in Scheme 4. Compound $\mathbf{1 5}$ reacts with NCS at two different sites (presumably the indole and the Trp-Pro tertiary amide), forming a dichlorinated intermediate. We believe that the rates of both chlorinations are very similar, as no monochlorinated species could be detected by mass spectrometry in reactions conducted without Pro-OBn. Then, the chlorine atom at the undesired site could be transferred to Pro-OBn, affording chlorinated amine 19 along with a monochlorinated intermediate which evolves into product upon addition of dipeptide $\mathbf{1 6}$ to the mixture. ${ }^{[22]}$ Elimination of $\mathrm{HCl}$ from 19 would produce imine $\mathbf{2 0}$ and sequester the chlorine atom as an $\mathrm{HCl}$ salt of the base (1,4-dimethylpiperazine, or possibly another equivalent of Pro-OBn). In support of this hypothesis, a dichlorinated intermediate, a monochlori nated intermediate, chloroamine 19, and imine $\mathbf{2 0}$ were all detected by mass spectrometry in oxidative coupling reactions with added Pro-OBn. Nonetheless, additional studies are required to determine the precise role of this additive. Finally, our ability to conduct successful indole-imidazole oxidative couplings without Pro-OBn in the synthesis of the model right-hand ring of $\mathbf{1}^{[7 \mathrm{a}]}$ can be understood by recognizing that the indole moiety in the prior substrate was less hindered and therefore more reactive than the indole of macrocycle 15. Consequently, the desired chlorination of the indole was significantly faster than the undesired chlorination, and only monochlorinated intermediates were formed in the presence of 1 equiv of NCS.

Consistent with our observations in the right-hand ring model system, ${ }^{\text {[7a] }}$ macrolactamization of $\mathbf{1 7}$ promoted by HOBt/HBTU provided bicyclic peptide $\mathbf{1 8}$ in high yield (83\%) with no evidence of epimerization. Then, exposure of $\mathbf{1 8}$ to TFA caused scission of both the Pbf and tert-butyl ester protecting groups, delivering 1 in $88 \%$ yield. Notably, and in agreement with prior studies, the Pbf moiety could be removed cleanly without complications arising from indole alkylation that have been observed with the 
related Pmc and Mtr groups ( $\mathrm{Pmc}=2,2,5,7,8$-pentamethylchroman-6-sulfonyl, $\mathrm{Mtr}=2,3,6$ trimethyl-4-methoxybenzenesulfonyl). ${ }^{[23]}$ Furthermore, no chromatographic purification of $\mathbf{1}$ was required as long as its immediate precursor $\mathbf{1 8}$ was carefully purified on $\mathrm{SiO}_{2}$.

The vast majority of signals in the ${ }^{1} \mathrm{H}$ NMR spectrum of synthetic $\mathbf{1}$ matched the spectrum of the natural product, and NOE correlations (indole NH/imidazole $\mathrm{H} 2$ and Trp $\beta-\mathrm{H} /$ imidazole H5) demonstrated that our synthetic material possessed the correct configuration about the heterobiaryl axis. ${ }^{[24]}$ However, the chemical shift of imidazole $\mathrm{H} 2$ differed significantly from the natural sample. Further investigations established the concentration, temperature, and $\mathrm{pH}$ dependence of this signal. ${ }^{[25]}$ Specifically, the imidazole $\mathrm{H} 2$ peak shifted upfield as the sample of $\mathbf{1}$ was diluted or as the temperature of the sample was increased. In contrast, this signal shifted downfield if TFA was added to the solution. We have observed this peak anywhere from $\delta=9.53$ to $8.04 \mathrm{ppm}$. Significantly, this range encompasses the reported chemical shift of imidazole $\mathrm{H} 2$ in the natural sample $(\delta=9.41$ ppm) ${ }^{[1]}$

Smaller, but analogous variations were observed with the imidazole H5 signal ( $\delta=7.83-$ 7.40 range, $7.79 \mathrm{ppm}$ in natural sample). It is likely that the imidazole $\mathrm{N} 3$ atom of $\mathbf{1}$ is involved in intermolecular hydrogen bonding and/or acid-base reactions, thereby perturbing the chemical shifts of neighboring atoms. Finally, an analytical sample of natural 1 was shown to be identical to our synthetic material by reverse-phase HPLC. ${ }^{[26]}$

In conclusion, we have completed the synthesis of celogentin $\mathrm{C}$. This work constitutes the first total synthesis of a member of the celogentin/moroidin family of bicyclic antimitotic peptides. The two unusual side chain cross-links were constructed by a Knoevenagel condensation-radical conjugate addition sequence (Leu-Trp linkage) and an indoleimidazole oxidative coupling (Trp-His linkage). The latter reaction was successful only upon use of Pro-OBn as an additive. The effect of Pro-OBn on the oxidative coupling is quite intriguing, and further studies are in progress to more clearly elucidate its role in the reaction. Additionally, we discovered an unusual dependence of the chemical shifts of the His imidazole hydrogen atoms of $\mathbf{1}$ on concentration, temperature, and $\mathrm{pH}$. Our route to $\mathbf{1}$ should provide access to other members of the celogentin/moroidin family, and their syntheses and anticancer activities will be the subjects of future investigations.

\section{Supplementary Material}

Refer to Web version on PubMed Central for supplementary material.

\section{References}

1. Kobayashi J, Suzuki H, Shimbo K, Takeya K, Morita H. J. Org. Chem. 2001; 66:6626. [PubMed: 11578213]

2. a Leung T-WC, Williams DH, Barna JCJ, Foti S, Oelrichs PB. Tetrahedron. 1986; 42:3333.b Kahn SD, Booth PM, Waltho JP, Williams DH. J. Org. Chem. 1989; 54:1901.

3. Celogentins A-C. reference [1]; Celogentins D-H, J, Suzuki H, Morita H, Iwasaki S, Kobayashi J. Tetrahedron. 2003; 59:5307.

4. Suzuki H, Morita H, Shiro M, Kobayashi J. Tetrahedron. 2004; 60:2489.

5. Yoshikawa K, Tao S, Arihara S. J. Nat. Prod. 2000; 63:540. [PubMed: 10785436]

Angew Chem Int Ed Engl. Author manuscript; available in PMC 2015 September 03. 
6. Morita H, Shimbo K, Shigemori H, Kobayashi J. Bioorg. Med. Chem. Lett. 2000; 10:469. [PubMed: 10743950 ] ${ }^{b}$ see also references [1] and [3].

7. a He L, Yang L, Castle SL. Org. Lett. 2006; 8:1165. [PubMed: 16524294] b Ma B, Litvinov DN, Srikanth GSC, Castle SL. Synthesis. 2006:3291.c Castle SL, Srikanth GSC. Org. Lett. 2003; 5:3611. [PubMed: 14507185]

8. a Bentley DJ, Moody CJ. Org. Biomol. Chem. 2004; 2:3545. [PubMed: 15592611] b Harrison JR, Moody CJ. Tetrahedron Lett. 2003; 44:5189.c Comber MF, Moody CJ. Synthesis. 1992:731.

9. Yuen AKL, Jolliffe KA, Hutton CA. Aust. J. Chem. 2006; 59:819.

10. Michaux J, Retailleau P, Campagne J-M. Synlett. 2008:1532.

11. For a total synthesis of the monocyclic peptide stephanotic acid methyl ester, see: Bentley DJ, Slawin AMZ, Moody CJ. Org. Lett. 2006; 8:1975. [PubMed: 16671760]

12. a Banerjee B, Capps SG, Kang J, Robinson JW, Castle SL. J. Org. Chem. 2008; 73:8973. [PubMed: 18947256] b He L, Srikanth GSC, Castle SL. J. Org. Chem. 2005; 70:8140. [PubMed: 16277340] c Srikanth GSC, Castle SL. Org. Lett. 2004; 6:449. [PubMed: 14748615]

13. For a review of radical conjugate additions, see: Srikanth GSC, Castle SL. Tetrahedron. 2005; 61:10377.

14. Details of this unsuccessful approach will be provided in a forthcoming full paper.

15. Synthesized by the coupling of Boc-Leu and Val-OBn (EDCI, HOBt, THF, 93\%) and subsequent Boc deprotection (TFA, $\mathrm{CH}_{2} \mathrm{Cl}_{2}$, quant.).

16. a Manjunatha SG, Chittari P, Rajappa S. Helv. Chim. Acta. 1991; 74:1071.b Manjunatha SG, Reddy KV, Rajappa S. Tetrahedron Lett. 1990; 31:1327.

17. Fornicola RS, Oblinger E, Montgomery J. J. Org. Chem. 1998; 63:3528.

18. The configuration of the alkene in 8 was assigned based on the X-ray crystal structure of a model compound: see reference [12b].

19. Boeckman RK Jr. Potenza JC. Tetrahedron Lett. 1985; 26:1411.

20. See Supporting Information for details. Minor product $9 \mathrm{~d}$ was carried through a sequence identical to that shown in Scheme 2, and the ${ }^{1} \mathrm{H}$ NMR spectrum of the resulting product $14 \mathrm{~d}$ matched well with the 2,3-anti diastereomer of stephanotic acid methyl ester prepared by the Moody group (compound diast-6 in reference [11]). Details of this work will be provided in a forthcoming full paper.

21. a Booker-Milburn KI, Fedouloff M, Paknoham SJ, Strachan JB, Melville JL, Voyle M. Tetrahedron Lett. 2000; 41:4657.b Bergman J, Engqvist R, St lhandske C, Wallberg H. Tetrahedron. 2003; 59:1033.c Engqvist R, Bergman J. Tetrahedron. 2003; 59:9649.

22. Dipeptide 16 is added to the reaction mixture $6 \mathrm{~h}$ after the other reagents; see Supporting Information for detailed procedure.

23. Fields CG, Fields GB. Tetrahedron Lett. 1993; 34:6661.

24. Regarding the NOE correlations observed with natural celogentin C, Figure 4 and the accompanying text of reference [1] are in error. The correct data can be located in Table 3 and on the NOESY spectrum given in Supporting Information. This discrepancy caused us previously to erroneously conclude that our model right-hand ring of celogentin $\mathrm{C}$ was the non-natural atropisomer (see reference [7a]).

25. See Supporting Information for spectra.

26. We were only able to obtain ca. $0.1 \mathrm{mg}$ of natural 1 . The presence of contaminants in this material precluded us from acquiring an informative ${ }^{1} \mathrm{H}$ NMR spectrum. 


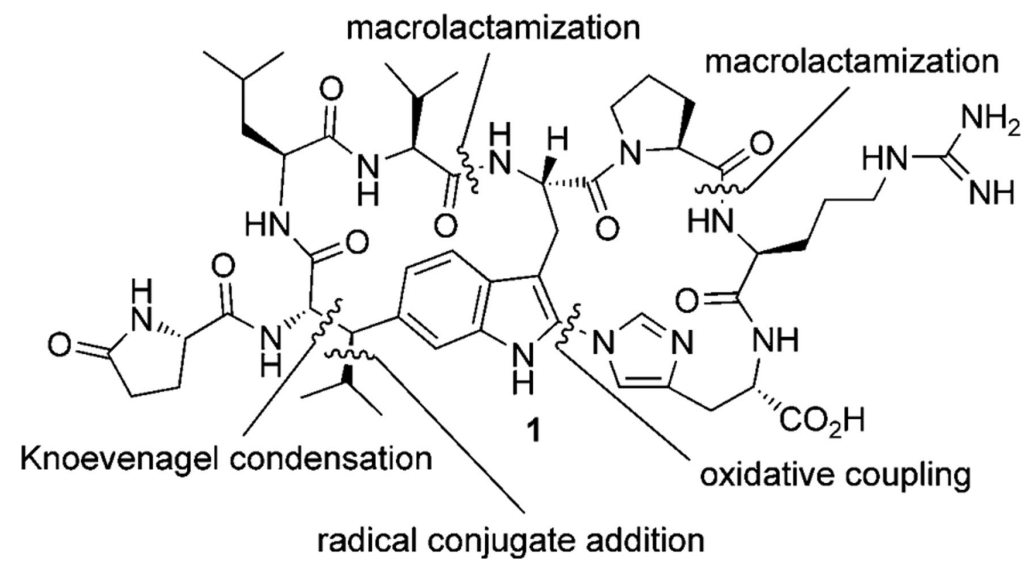

Figure 1.

Celogentin C and synthetic plan. 

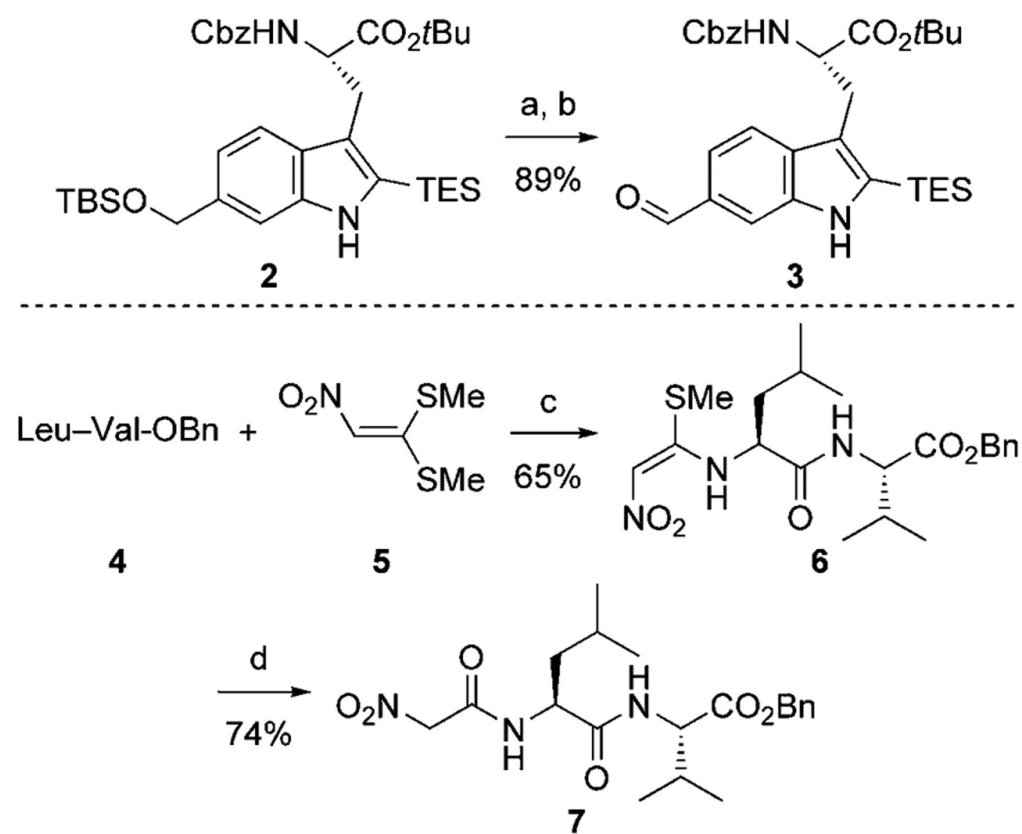

Scheme 1.

Synthesis of Knoevenagel condensation partners. Reagents and conditions: a) $\mathrm{AcOH} / \mathrm{THF} / \mathrm{H}_{2} \mathrm{O} 3: 2: 2$; b) DDQ, $\mathrm{CH}_{2} \mathrm{Cl}_{2}, 0^{\circ} \mathrm{C}$; c) TsOH (0.1 equiv), MeCN, reflux; d) $\mathrm{HgCl}_{2}, \mathrm{MeCN} / \mathrm{H}_{2} \mathrm{O} 3: 1 . \mathrm{Cbz}=$ benzyloxycarbonyl, TBS =tert-butyldimethylsilyl, $\mathrm{TES}=$ triethylsilyl, DDQ =2,3-dichloro-5,6-dicyano-1,4-benzoquinone, $\mathrm{TsOH}=p$ toluenesulfonic acid. 
<smiles>CC(C)C[C@H](NC(=O)C(=Cc1ccc2c(C[C@H](NC(=O)OCc3ccccc3)C(=O)OCC(C)(C)C)c(C(F)(F)F)[nH]c2c1)C(=O)OCc1ccccc1)C(C)C</smiles>

8

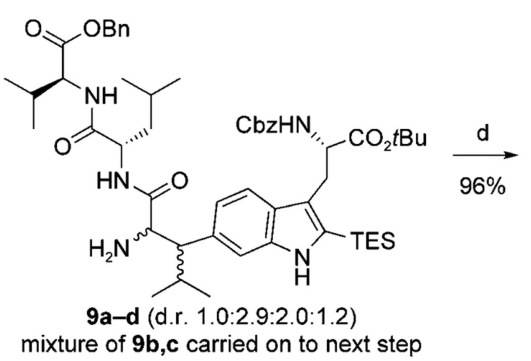

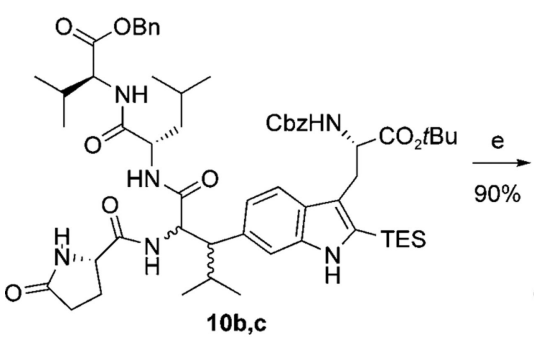<smiles>CC(C)CC(C)C(=O)N[C@H](C(=O)O)C(C)C</smiles>

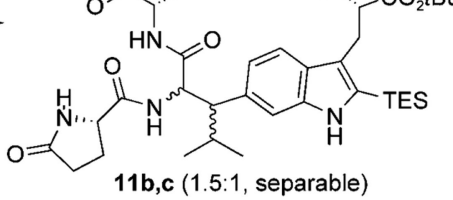<smiles>[131In]</smiles>
$91 \%$

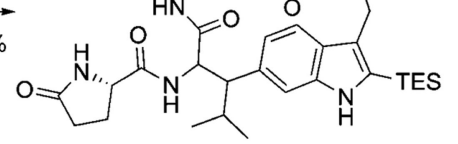

11b,c (1.5:1, separable)

$12 b$

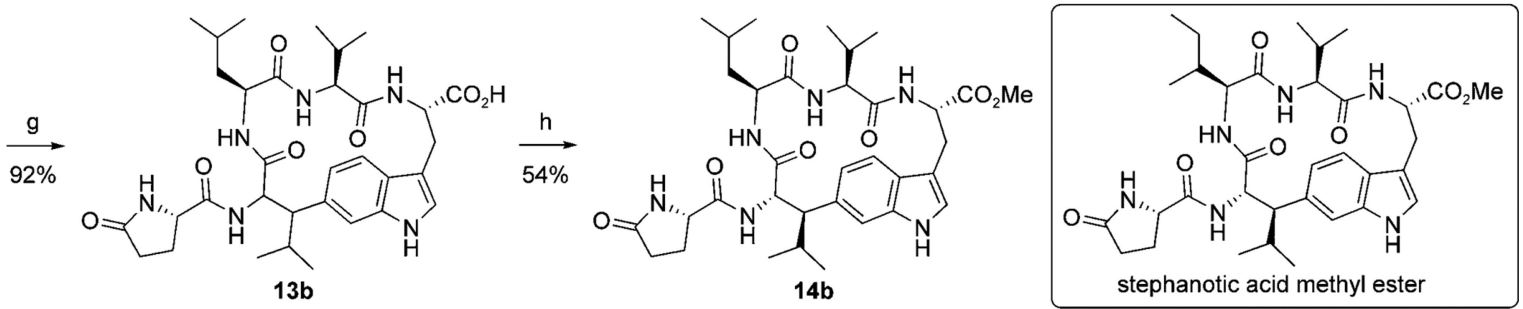

Scheme 2.

Synthesis of left-hand ring. Reagents and conditions: a) $\mathrm{TiCl}_{4}, \mathrm{NMM}, \mathrm{THF} / \mathrm{Et}_{2} \mathrm{O} 2: 1$; b) $\mathrm{Et}_{3} \mathrm{~B}, \mathrm{O}_{2}, \mathrm{Zn}(\mathrm{OTf})_{2}, i \mathrm{PrI}, \mathrm{Bu}_{3} \mathrm{SnH}, \mathrm{CH}_{2} \mathrm{Cl}_{2},-78^{\circ} \mathrm{C}$; c) $\mathrm{SmI}_{2}, \mathrm{MeOH}$; d) pyroglutamic acid, EDCI, HOBt, THF, $0^{\circ} \mathrm{C}$ to RT; e) $10 \% \mathrm{Pd} / \mathrm{C}, \mathrm{HCO}_{2} \mathrm{NH}_{4}, \mathrm{MeOH} / \mathrm{H}_{2} \mathrm{O} 5: 1$; f) $\mathrm{HOBt}, \mathrm{HBTU}$, DMF, $0^{\circ} \mathrm{C}$ to RT; g) $\mathrm{BCB}, \mathrm{CH}_{2} \mathrm{Cl}_{2}$; h) $\mathrm{SOCl}_{2}, \mathrm{MeOH}$. NMM=N-methylmorpholine, $\mathrm{THF}=$ tetrahydrofuran, EDCI $=N$-(3-dimethylaminopropyl)- $N^{\prime}$-ethylcarbodiimide hydrochloride, $\mathrm{HOBt}=1$-hydroxybenzotriazole, HBTU $=O-($ Benzotriazol-1-yl $)-N, N, N^{\prime}, N^{\prime}-$ tetramethyluronium hexafluorophosphate, $\mathrm{DMF}=N, N$-dimethylformamide, $\mathrm{BCB}=B$ bromocatecholborane. 

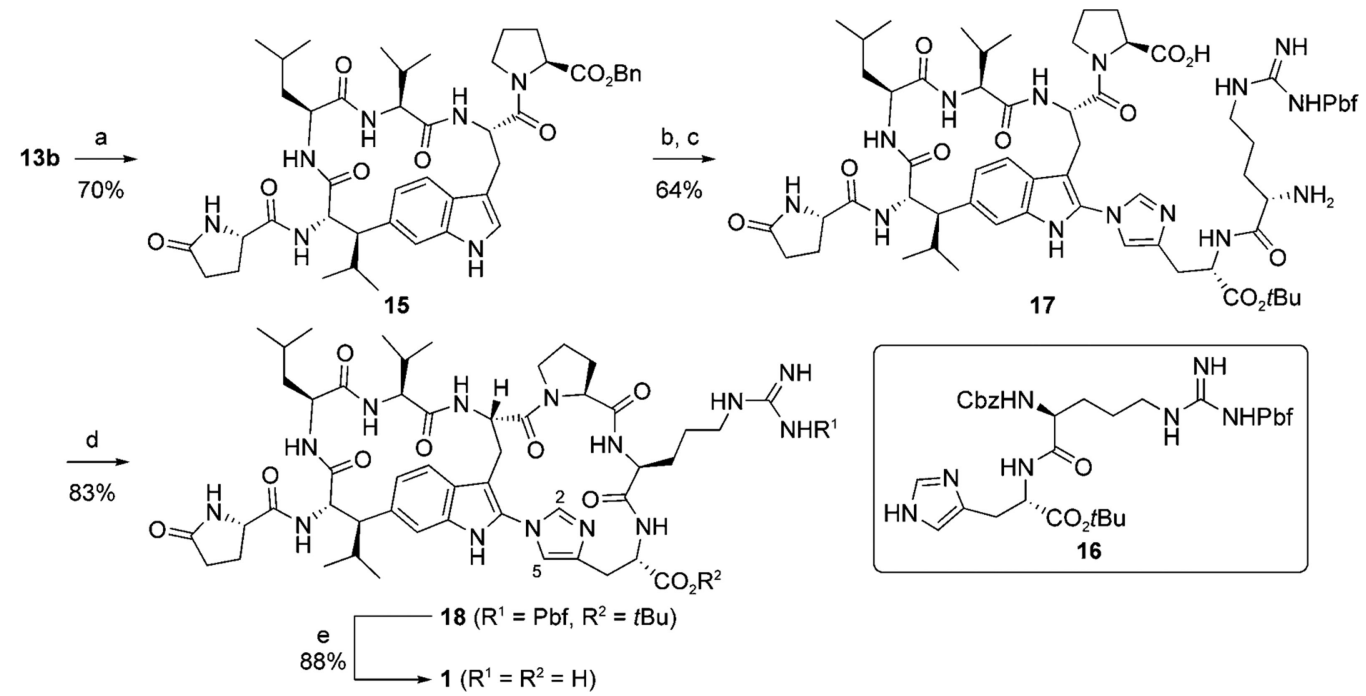

Scheme 3.

Completion of the synthesis of $\mathbf{1}$. Reagents and conditions: a) Pro-OBn, EDCI, HOBt, THF, $0^{\circ} \mathrm{C}$ to RT; b) Pro-OBn (2 equiv), NCS (3 equiv), 1,4-dimethylpiperazine, $\mathrm{CH}_{2} \mathrm{Cl}_{2}$ then $\mathbf{1 6}$ (5 equiv); c) $10 \% \mathrm{Pd} / \mathrm{C}, \mathrm{HCO}_{2} \mathrm{NH}_{4}, \mathrm{MeOH} / \mathrm{H}_{2} \mathrm{O} 5: 1$; d) $\mathrm{HOBt}$, HBTU, DMF; e) TFA/ $\mathrm{H}_{2} \mathrm{O}$ 9:1. $\mathrm{Pbf}=2,2,4,6,7$-pentamethyldihydrobenzofuran-5-sulfonyl, $\mathrm{NCS}=\mathrm{N}$-chlorosuccinimide, $\mathrm{TFA}=$ trifluoroacetic acid. 


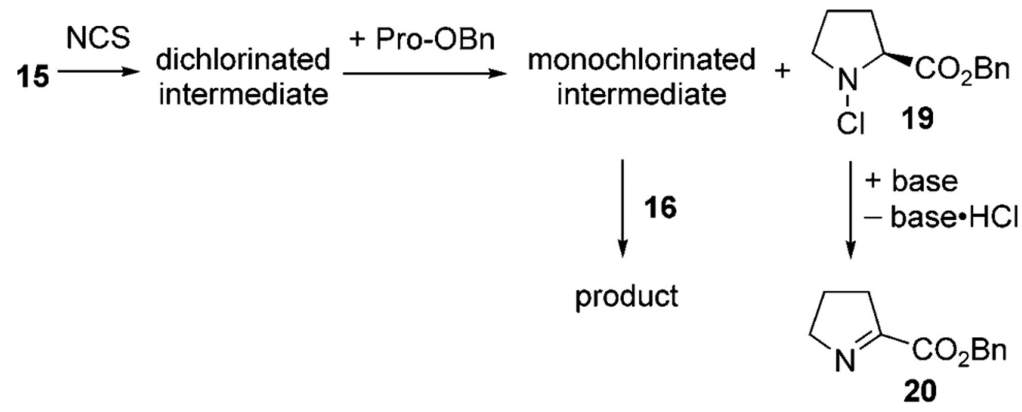

Scheme 4.

Possible role of Pro-OBn in oxidative coupling. 